\title{
Economic and Social Contradictions in the Implementation of Corporate Social Responsibility of Companies
}

\author{
Alla Bylinskaya ${ }^{1},{ }^{*}$ Tatiana Loginova ${ }^{1}$ \\ ${ }^{I}$ National Research Lobachevski State University of Nizhni Novgorod, Russia \\ *Email:alla_bylinskaya@mail.ru
}

\begin{abstract}
The relevance of the research topic is related to the denationalization of the social services market and, as a result, the increasing importance of issues of social responsibility, an important role in solving which belongs not only to the state, but also to the non-state sector. The key problem of Russian practice is the lack of mass interest of both large companies and small and medium-sized businesses in addressing issues of corporate social responsibility and social investment. The purpose of the study is to identify contradictions in the implementation of corporate social responsibility. Achieving this purpose is carried out by implementing and evaluating the results of a sample survey of company management representatives from the perspective of benefits and risks associated with the acceptance and non-acceptance of social obligations. The research is carried out using the tools of content analysis of survey results and in-depth interviews of company representatives. The methodological basis for evaluating the results of an empirical study is the stakeholder approach to analyzing the attitude of business to corporate social responsibility. The testable hypothesis is the assumption that companies agree to accept social responsibility only when they can benefit from it. Based on the conducted research, it is proved that the interpretation of corporate social responsibility should be based on the understanding of the opposite of the objective economic interests of stakeholders. The conducted research led to the conclusion that in order to strengthen their positions and ensure the prospects for development, companies, despite their desire to benefit from interaction, will engage in non-profitable social activities that benefit society and make social investments.
\end{abstract}

Keywords: Corporate social responsibility, Social investment, Corporate strategy, Stakeholder approach, Competitiveness, Social obligations.

\section{INTRODUCTION}

The article deals with the issues of interest of companies in solving issues of corporate social responsibility from the perspective of benefits and risks associated with the acceptance and non-acceptance of social obligations. The study is based on the stakeholder approach to assessing the attitude of business to corporate social responsibility, which is based on the hypothesis that companies are willing to participate in solving social responsibility issues mainly because they can benefit from such participation. Thus, the study is based on the interpretation of social responsibility, which is able to cover this important feature. This article attempts to substantiate that the understanding of corporate social responsibility should be based on the knowledge of the opposite of the objective economic interests of stakeholders and should be able to cover both its economic and social aspects. Based on the assumption that companies are forced to take into account not only their own interests, but also the long-term needs and interests of society, it is concluded that in order to maintain and strengthen their positions in the market, they, despite their desire to minimize costs, engage in activities that benefit society and minimize the negative consequences of their activities. 


\section{MATERIALS AND METHODS}

The theoretical and methodological basis of the research is formed by the works of domestic and foreign authors. Among the foreign authors should be named G. Bowen, who proposed the first approach to the definition of the concept of "Social responsibility" [1], M. Palazzi and J. Statcher, who considered social responsibility from a behavioral perspective [2], A. Carroll, who proposed the distribution of levels of corporate social responsibility [3], S. Vartik and F. Kohren, who developed a model of corporate social activity [4], D. Wood, who proposed a comprehensive model of corporate social activity [5], M. Clarkson, who studied the relationship between social responsibility and management priorities [6].

Among the works of Russian authors, a significant contribution to the development of the theory of corporate social responsibility was made by the works of I.Yu. Belyaeva [7], A.D. Zaretskiy [8], L.I. Polishchuk, [9] I.N. Tkachenko [10].

The scientific novelty of the study consists of the purpose and objectives of the study and introduces an attempt to systematize the assessment of corporate social responsibility from the position of unity and opposition of the objective economic interests of society and companies, as well as by comparing the situation in Russia with the practices of international experience. The problem under study is to assess the effectiveness of existing models of corporate social responsibility (CSR) of business in Russia, and identify prospects for overcoming the inefficiency of existing CSR models based on the results of the research. The socioconstructionist approach suggests the need to further construct social problems in the field of CSR, the structural-functional approach is the description of the place of CSR in the civil society and the analysis of carried out functions; the systemic approach is the analysis of the role of CSR in the system of social relations in the close relationship between structures, institutions and processes of modern Russia.

The research uses approaches and methods aimed at solving theoretical and practical research problems. The theoretical basis will be based on the system, structuralfunctional and problemological approaches taken together, which make it possible to form the conceptual apparatus of research and interpret the basic concepts in a socio-scientific context. As empirical methods aimed at collecting and processing information, the following methods are used:

1. In-depth interviews with representatives of companies responsible for solving CSR issues, with representatives of target groups that are targeted by their activities to form a CSR system. Based on the results of in-depth interviews, a survey toolkit has been developed.
2. The questionnaire surveys, based on which a quantitative and qualitative assessment of the economic and social effects of CSR implementation is carried out, both from the point of view of the companies themselves, and their customers and society.

3. The content analysis of open sources devoted to the activity of companies in the field of CSR, assessment of their resource potential and effectiveness in various areas of social functioning.

\section{RESULTS AND DISCUSSION}

The study was conducted in two stages. The first stage is theoretical and methodological. The second stage is empirical and analytical.

The result of the theoretical and methodological stage is the development and refinement of the methodological basis for conducting empirical research by critically rethinking existing domestic and foreign approaches to the problem under study.

The basic procedures implemented in the first stage:

1. The analysis of existing theoretical approaches to the study of the problems of corporate social responsibility, the approval of the methodological foundations of the research, the nomination of working hypotheses and the formation of the research program.

2. The conducting a series of pilot studies to test the questionnaires, the identification of the need for the adjustments and the development of the adjusted version.

3. The preparation of materials for publications on the theoretical part of the work. At this stage, a scientific article was published in the collection of scientific works "Civil society in Russia: challenges of our time" [11], and a scientific article "State, business and NCO: the formation of a new model of interaction and evaluation of its effectiveness" in the collection of materials of the conference "International Scientific-Practical Conference "Transformation of Corporate Governance Models under the New Economic Reality" (Ekaterinburg, the Russian Federation, November 20, 2020)" (ConfCorp 2020) was prepared for the publication.

During the second, empirical-analytical stage of the work, the planned research procedures were implemented, which ensured the formation of an array of data that ensured the implementation of their meaningful analysis.

It is planned to build frequency and linear distributions according to the research parameters, crosstables, multidimensional data analysis, the identification of functional dependencies of research parameters, etc., the preparation of publications based on the results of an empirical study of models of corporate practices in civil society. 
The study analyzed the results of in-depth interviews with the managers of large companies responsible for CSR-representatives of the best CSR practices in Russia from various industries and economic activities. During the study the authors were guided by the data of the project implemented by the Association of managers of Russia with the support of the Russian Government, funded by the Development programme of the United Nations (UNDP). The study was aimed at identifying and analyzing the deep changes that occur in the long term in both the industry and the organizational structure of socially responsible businesses, as well as in the volume and structure of social investments to address the question of how the social portrait of socially responsible entrepreneurship in Russia has changed.

Based on the research of the content of "Reports on social investments in Russia" for 2004, 2009, 2014 and 2019 , a steady downward trend in the number of survey participants was revealed. For example, if in 2003102 respondents took part in the survey, by 2014 their number had decreased to 60 , and in 2018 it was only 45 , which is evidence of a decrease in the information openness of the Russian companies.

The results of the analysis of "Reports on social investments in Russia" for 2004, 2009, 2014 and 2019 indicate a relatively uniform distribution of industry among the participants and leaders of companies operating in the field of services (38\%), the representatives of the commodity sector $(33 \%)$ and the representatives of the manufacturing industry (29\%).

Despite the fact that more than 15 years have passed since the beginning of the research on the project of the Association of Managers, implemented with the assistance of the Social Investment Fund "Report on social investment in Russia", over the past period, no radical positive changes in the volume of social investment were revealed according to the results of the conducted research.

Table 1 presents the data on the dynamics of social investment in Russia at comparable prices.

In 2018, the representatives of the companies participating in the survey refused to provide information on the volume of social investments [12, p.55], which, in our opinion, is evidence of distrust and unwillingness to conduct a dialogue on this issue.

In this regard, the authors consider it necessary to conduct a study of the conflicting interests of the parties in order to identify the ways to overcome the contradictions that should ensure the creation of conditions for the effective implementation of social responsibility of companies.

The proposed approach is based on the assumption that by engaging in interaction and assuming certain obligations, the actors act in the interests of achieving personal or corporate benefits. Any investment decision is always associated with the rejection of alternative investment opportunities. Based on this, it is necessary to consider the social responsibility of business in two ways: on the one hand, as a factor contributing to the development and strengthening of the company's position in the market, on the other hand, as a factor inhibiting its development.

Social responsibility as a factor of company development has a number of manifestations:

- high social responsibility is a factor in the growth of the company's competitiveness as an employer;

- high positions of the company's management in the rating of TOP-50 managers on corporate social responsibility form the company's reputation and indicate the high professionalism of its managers;

- high social responsibility provides conditions for sustainable development of the company;

Social responsibility as a factor inhibiting the development of the company also has a number of manifestations:

- the growth of social investment contributes to an increase in the company's expenses;

- the return on social investment is difficult to measure;

- the changes in the volume of social investments do not affect the competitiveness of individual types of products of the company.

Table1. Volumes of social investments of Russian companies*

\begin{tabular}{|l|c|c|c|c|}
\hline & 2003 & 2008 & 2011 & 2018 \\
\hline $\begin{array}{l}\text { Social investments per employee, total: } \\
\text { thousand rubles* }\end{array}$ & 62.19 & 78.9 & 48.1 & - \\
\hline $\begin{array}{l}\text { The ratio of the magnitude of social } \\
\text { investments to gross sales, \% }\end{array}$ & 1.96 & 3.76 & 8.56 & - \\
\hline $\begin{array}{l}\text { Share of social investments in the balance } \\
\text { sheet profit, \% }\end{array}$ & 11.25 & 6.25 & 3.43 & - \\
\hline
\end{tabular}

*Based on the data from "Reports on social investments in Russia" for 2004, 2009, 2014 and 2019

**Cost figures are given in comparable prices 
Based on this, we will consider the social responsibility of the company as a condition for achieving competitive advantages, guided by the approach of Robert Grant, according to which the achievement of competitive advantages of the company is possible only thanks to those advantages and product positions in which this company is significantly ahead of competitors and which other firms can neither copy nor repeat. One of these advantages, according to the results of the study conducted by the authors, is corporate social responsibility. The survey showed the significance of this parameter.

The authors consider the resource approach of $\mathrm{R}$. Grant, which is based on the idea of "distinctive" abilities of the company, to be particularly relevant for assessing the prospects for implementing social investments. The achievement of distinctive abilities in the short term is impossible and requires not only time, but also resource costs. In the context of constantly changing market conditions, the company also needs permanent work on the search and development of new abilities. This makes it possible in the future to provide a solution to a wide range of objectives, in particular, as emphasized by E.K. Timofeeva "Evaluating the performance of activities and making the necessary changes allows you to adjust the list of existing stakeholders and find new ones" [13, p.47].

In order to analyze the resources and abilities, we will use the scheme formed on the basis of the approach of R. Grant who developed a model, including five stages (fig. 1).

The first step is to perform the organization's resources available for the realization of social investment, to make their rating in comparison with competitors, identifying the strengths and weaknesses of resource provision companies, defining a list of resources that can participate in the formation of a "distinctive" capabilities of the firm. The next stage requires an analysis of "distinctive " abilities as a potential source of formation of sustainable competitive advantages of the company. The third stage involves fixing the possibilities of forming and retaining the main "distinctive" abilities of the company. Further work is related to the choice of a strategy that allows for the most profitable use of the firm's "distinctive" abilities, taking into account the influence of external factors. The final stage requires the identification of resource problems and involves the development of measures to effectively overcome them. (figure 1.).

The main difficulty lies in the fact that the firm's "distinctive" abilities and resources are the basis for development and success over a certain limited period of time. In order to ensure sustainable competitive advantages, improvement activities are required on a regular basis. The practical application of the proposed model should take into account an important circumstance emphasized by a number of authors. For example, the classic of strategic marketing, Zhan-Zhak Lambin believed that resources are the basis for identifying abilities, and you need to constantly identify abilities by analyzing the resource capabilities of competitors [14, p.89].

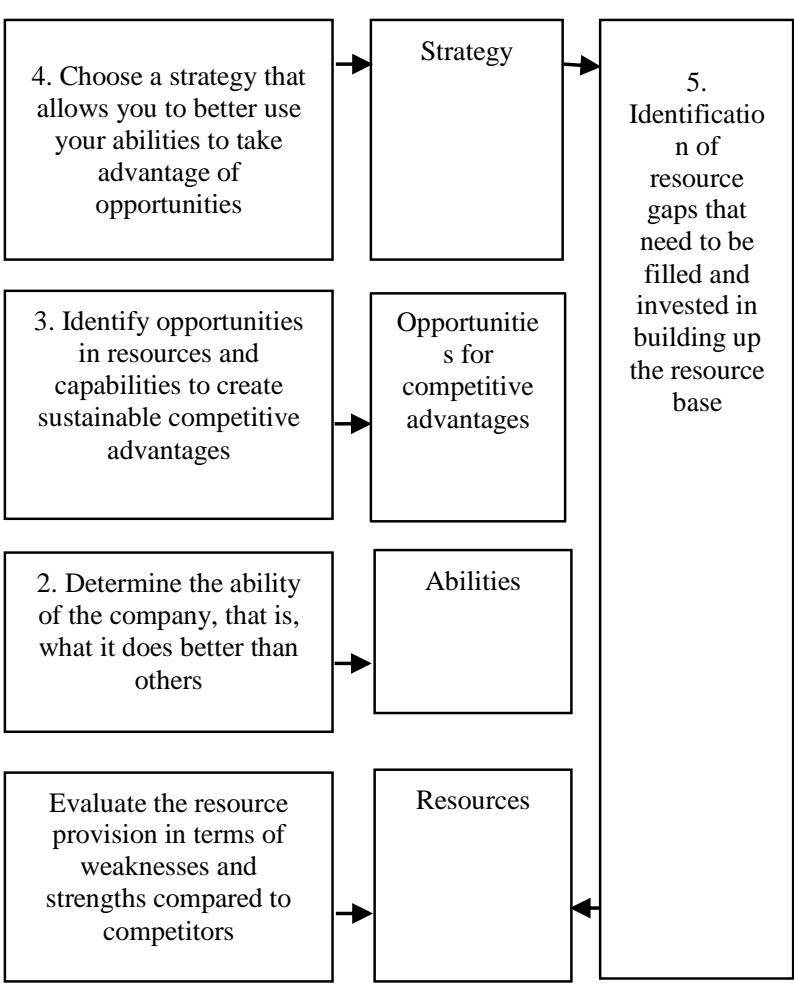

Figure 1 Analysis of the company's resources and capabilities.

The analysis of "distinctive" abilities allows the organization to identify its key competencies, which the authors attribute to the competitive advantages of the company that ensure its success.

The formation of key competencies can be schematically represented in the form of a simple logical scheme, which is shown in figure 2 .

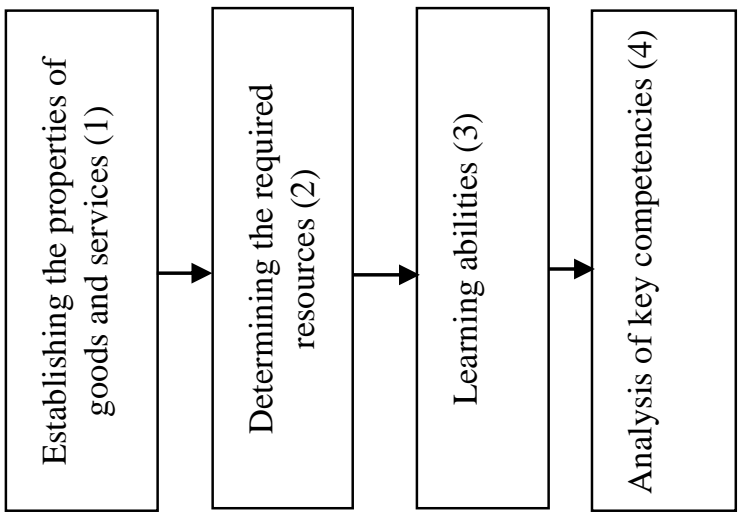

Figure 2 Sequence of formation of key competencies.

To develop a company's strategy, it is necessary to identify organizational implementation capabilities based on resource analysis and identify key success factors, that 
is, those capabilities of the organization that will ensure success in the market. The developed strategy is designed to provide the organization with competitive advantages. The strategy formation model is shown in figure 3 .

Today, in the world and Russian practice, companies in general have formed an understanding that the implementation of the company's development strategy requires the inclusion of CSR issues in the number of strategic priorities. This is evidenced by the results of our pilot study, which showed that among the respondents there is an understanding of the sustainable relationship between the company's success and its CSR. The research results presented in "The report on social investment in Russia-2019 "(hereinafter referred to as the "Report") also confirm "the existing understanding of the strategic nature of CSR by respondent companies". [12, p.21]. According to the data provided in the "Report", $91 \%$ of the surveyed representatives of companies accept the thesis about the corporate nature of CSR.

\begin{tabular}{|c|c|c|}
\hline $\begin{array}{c}\text { Competitive } \\
\text { advantages }\end{array}$ & $\begin{array}{c}\text { Key success } \\
\text { factors }\end{array}$ \\
\hline \multicolumn{3}{|c|}{ Organizational skills } \\
\hline Material & Resources \\
\hline Financial & Technology & $\begin{array}{c}\text { Specialized } \\
\text { anowledge and } \\
\text { skills }\end{array}$ \\
Physical & Reputation & $\begin{array}{c}\text { Ability to } \\
\text { communicate } \\
\text { and interact }\end{array}$ \\
Culture & \begin{tabular}{c} 
Motivation \\
\hline
\end{tabular} &
\end{tabular}

Figure 3 Company strategy formation model.

The share of Russian organizations that develop and implement corporate strategies as socially responsible is steadily increasing, amounting to $36 \%$ in 2019 against $29 \%$ in 2014 . This could be considered as a positive trend, but the contradiction lies in the results of the same studies showing that only half of respondents in 2019 recognized their companies' CSR strategies as an integral part of the company's corporate strategy. This demonstrates a weak link between the strategic priorities of companies' development and their policies, and indicates a low quality of management.

In connection with the results obtained, the question should be raised about the prospects for the transformation of models of corporate social values and corporate social activity. It is obvious that it is inevitable to change the "win-win" paradigm (the shared value model) and the corporate social activity model based on it (the corporate sustainability model 2.0), and to move to the "lose-win" paradigm and the corresponding corporate sustainability model 3.0. This model assumes "a greater immersion of business in the creation of social value with a possible change in the prevailing paradigm to lose-win with appropriate cooperative schemes that allow companies to maintain their competitiveness" [15].

To date, only half of Russian companies associate following the principles of CSR with opportunities to increase the profitability of the company. This is a direct consequence of the rejection of the "lose-win" paradigm by others and the incorrect assessment of the effects that arise in the absence of income.

\section{CONCLUSIONS}

1. The study demonstrated that Russian companies are following the path of forming a socially responsible business through the transformation of their functional strategies, implementing the principles of CSR in financial, production, management and marketing strategies, as well as in $\mathrm{R} \& \mathrm{D}$ and human resources management strategies.

2. The main long-term goals of Russian companies in the field of CSR are to increase competitiveness and obtain long-term competitive advantages.

3. Medium-term goals can include building and maintaining a reputation and reducing risks.

4. Despite the awareness of the need to include CSR priorities among the company's strategic priorities, real practices do not indicate that for most companies CSR has not yet become a full-fledged part of the corporate strategy.

5. The highest priority goal of most Russian companies continues to be the achievement of long-term competitive advantages, which indicates an outdated value system that exists within the framework of the "corporate sustainability 1.0 " model, which ranks goal setting on this priority basis.

6. A number of companies have not yet created a "shared", "shared value", despite the fact that over the past five years, from 2014 to 2019, the share of companies in which "shared value" has increased significantly.

7. Despite the fact that most companies have a "common value", there is a problem of its non-use in the interaction of the company with society.

8. There is an increase in companies that include the solution of social and environmental problems among the goals of their activities, while at the same time reducing the interest in creating value for shareholders. 


\section{REFERENCES}

[1] H.R. Bowen, Social Responsibilities of the Businessman, New York, Harper, 1953, 276 p.

[2] M. Palazzi, J.K. Statcher, Corporate social responsibility and success in business, Moscow: "Human rights", 1997, 59 p. (In Russ.).

[3] A.B. Carrol, Corporate social responsibility: the centerpiece of competing and complementary frameworks, Organizational dynamics Vol. 44 No. $2 \quad$ (2015) 87-96. DOI: http://www.Dx.Doi.Org/10.1016/j.Orgdyn.2015.02 .002

[4] S.L., Wartick, P.L. Cochran, The Evolution of the Corporate Social Performance Model, Academy of Management Review Vol. 10 Iss. 4 (1985) 758-769. DOI:

https://journals.aom.org/doi/full/10.5465/amr.1985. $\underline{4279099}$

[5] D.J. Wood, Corporate Social Performance Revisited, Academy of Management Review Vol.16 Iss. 4 (1991) 691-718. DOI: https://journals.aom.org/doi/epub/10.5465/amr.199 $\underline{1.4279616}$

[6] M.B.E. Clarkson, A Stakeholder Framework for Analysing and Evaluating Corporate Social Performance, Academy of Management Review, Vol. 20 Iss. 1 (1995) 92-117. DOI: https://journals.aom.org/doi/full/10.5465/amr.1995. $\underline{9503271994}$

[7] Corporate social responsibility: managerial aspect: monograph, edited by I.Yu. Belyaeva, M.A. Eskindarova, M.: KNORUS, 2008, 504 p. (In Russ.).

[8] A.D. Zaretsky, Corporate social responsibility: world and domestic practice: textbook, A.D. Zaretsky, T.E. Ivanova, Krasnodar, KSEI, 2012, 231 p. (In Russ.).

[9] L. Polischuk, Corporate Social Responsibility vs. Government Regulation: Institutional Analysis with an Application to Russia, Voprosy Economiki, Iss. 10, 2009. DOI: https://doi.org/10.32609/00428736-2009-10-4-22 Retrieved from: https://www. vopreco.ru/jour/article/view/931?locale=en_US

[10] I.N. Tkachenko, On the issue of the stakeholder model in the new paradigm of corporate governance, Architecture of Finance: illusions of global stabilization and prospects for economic growth, 2019, pp. 375-379. DOI: https://www.elibrary.ru/download/elibrary 414962 42 12152993.pdf (In Russ.)
[11] A.A. Bylinskaya, The role of trade unions in the formation of civil society in modern Russia, Civil society in Russia: challenges of modernity, 2016, pp. 190-195, Ulyanovsk state technical university, Ulyanovsk. Retrieved from: http://venec.ulstu.ru/lib/disk/2016/179.pdf Russ.)

[12] Report on social investment in Russia-2019: towards business transformation in the interests of sustainable development. Retrieved from: https://amr.ru/upload/iblock/435/4356def1f8d2cbe b228da1e761fec5ee.pdf (In Russ.)

[13] E.K. Timofeeva, Corporate social responsibility: sustainable development and interaction with stakeholders Iss. 4 (2015) 44-49. Retrieved from: https://www.elibrary.ru/download lelibrary 23662934 31262338.pdf (In Russ.)

[14] Lambin, Jean Jacques. Market-driven management: Strategic and operational marketing, Jean-Jacques Lambin. - Basingstoke (Hants); London: Macmillan press, 2000, XXVII, 737p., p. 50.

[15] R. Sardá, S. Pogutz, Corporate Sustainability in the 21st Century: Increasing the Resilience of SocialEcological Systems, Rutledge: London \& New York, 2019, pp. 48-53. DOI: https://doi.org/10.4324/9781315180908 Retrieved from: https://www.routledge.com/CorporateSustainability-in-the-21st-Century-Increasing-the$\underline{\text { Resilience/Sarda-Pogutz/p/book/9781138744653 }}$ 